\title{
Alat Pengering Gabah Berbasis Microcontroller Dengan Sensor DHT22
}

\author{
Khairul Hazhar ${ }^{1}$, Juli Sardi ${ }^{2}$ \\ 1,2Universitas Negeri Padang \\ Jl. Prof Dr. Hamka Air Tawar, Padang, Indonesia \\ khairulhazhar@gmail.com1 julisardi@ft.unp.ac.id²
}

\begin{abstract}
The arrangement of moisture on rice is an essential factor in the quality of grain. One of the problems farmers face today is the difficulty of curing grain because the harvesting process of farmers still USES sunlight and requires erratic time. The research was intended to create a grain dryer automatically using a DHT22 sensor. The research made up a prototype of hardware, which includes arduino uno, heater, dht22 sensors, fan, relays, buzzer, and LCD and software arduino uno as the control center of the device. After a few experiments, all the components in this system are able to work in accordance with the purpose of the research. This could be an alternative to the farmers' lowering water levels of rice.
\end{abstract}

Keywords - drier, arduino uno, sensor DHT22, heater, buzzer, LCD.

Abstrak- Pengaturan kelembaban air pada gabah merupakan faktor yang sangat penting dalam menentukan mutu gabah. Salah satu permasalahan yang dihadapi oleh petani saat ini adalah mengalami kesulitan dalam proses pengeringan gabah karena proses penjemuran gabah petani masih mengunakan sinar matahari dan membutuhkan waktu yang tidak menentu. Penelitian ini bertujuan untuk membuat alat pengering gabah secara otomatis mengunakan sensor DHT22. Penelitian ini membuat prototipe yang terdiri dari pembuatan perangkat keras (hardware) yang meliputi arduino uno, heater, sensor DHT22, fan, relay, buzzer, dan LCD dan perangkat lunak (software) arduino uno digunakan sebagai pusat kontroller dari alat ini. Setelah dilakukan beberapa percobaan, semua komponen dalam siytem ini mampu bekerja sesuai dengan tujuan penelitian. Alat ini bisa menjadi salah satu alternatif yang bisa diterapkan oleh petani dalam menurunkan kadar air pada gabah.

Kata kunci- pengering gabah, arduino uno, sensor DHT22, heater, buzzer, fan, LCD.

\section{Pendahuluan}

Indonesia merupakan negara agraris dimana sebagian besar lahan digunakan untuk petanian. Petanian merupakan bidang yang sangat penting dalam mencukupi kebutuhakan pokok masyarakat[1][2]. namun permasalahan yang ditemui dilapangan, proses pengering gabah masih dilakukan secara manual [3]. Salah satunya adalah petani masih mengunakan cara tradisional, seperti menjemur di bawah sinar matahari dengan waktu penjemuran bergantung pada cuaca yang tidak menentu [4]. Sehingga memperlambat proses pengeringan dan jika hujan penjemuran harus segera di angkat karna dapat merusak proses pengeringan.

Adapun salah satu faktor untuk mengatasi permasalahan pada proses pengeringan paska panen, dibutuhkan sebuah alat pengering gabah yang dimana dapat mengatur suhu panas dan kelembaban pada gabah supaya tidak mengalami kerusakan atau melebihi ambang batas yang dimana dapat merusak mutu beras[5]. oleh karena itu dibutuhkan proses penurunan kadar air[6], yang dimana Gabah kering panen (GKP) mempunyai kadar air antara 20\% - 27\%(basis basah). Berdasarkan
Standar Nasional Indonesia. Untuk kualitas gabah kering giling (GKG) membutuhkan kadar air 14\% agar dapat disimpan dalam jangka waktu 6 bulan[7].

Salah satu contoh penelitian tentang proses pengeringan gabah yang berjudul perancangan pengeringan gabah menggunakan pemanas udara dari tungku sekam, dimana pada proses pengeringan ini mengunakan tungku sekam sebagai sumber panas untuk proses pengeringan gabah dan masih terdapat kelemaban pada proses ini dimana panas yang dihasilkan oleh tungku sekam sangat bergantung pada bahan bakar kayu sebagai sumber untuk menghidupkan api[8]. Selain itu juga terdapat penelitian tentang sistem kontrol pengering gabah berbasis arduino dengan sensor hujan dan sensor berat, dimana pada penelitian ini masih terdapat kelemahan sistem yang telah dibuat yaitu dimana tidak dapat mengukur suhu dan kelembaban secara langsung melainkan penelitian ini hanya dapat mengukur sensor hujan dan berat pada gabah[9].

Berdasarkan penelitian diatas penulis berinovasi membuat alat pengering gabah berbasis arduino uno dengan sensor DHT22, yang dimana sistem pengering dapat menurunkan kadar air pada gabah padi dan dapat 
mengatur suhu panas pada pengeringan padi supaya tidak melebihi ambang batas yang ditentukan. Pada alat ini microcontroler arduino sebagai pengendali utama, motor dc untuk pengadukan gabah, sensor DHT22 sebagai pembaca suhu dan kelembaban pada gabah dan ruang pengering gabah, heater sebagai sumber panas dalam pengeringan gabah dan LCD yang menampilkan waktu,tanggal, kondisi proses pengeringan suhu dan kelembaban pada gabah .

\section{METODE}

Metode yang dilakukan dalam penelitian ini adalah membuat alat pengering gabah otomatis berbasis microcontroller dengan sensor DHT22 serta pelaksanaan percobaan pengujian pada masing-masing komponen.

\section{A. Blok Diagram}

Secara keseluruhan alat pengering gabah otomatis berbasis microcontroller dengan sensor DHT22. Terdiri dari beberapa bagian, yaitu: input berupa sensor kelembaban dht22, serta output berupa Driver relay, Motor DC, fan, buzzer, heater dan LCD. Berikut blok diagram dari alat seperti dibawah ini[10].

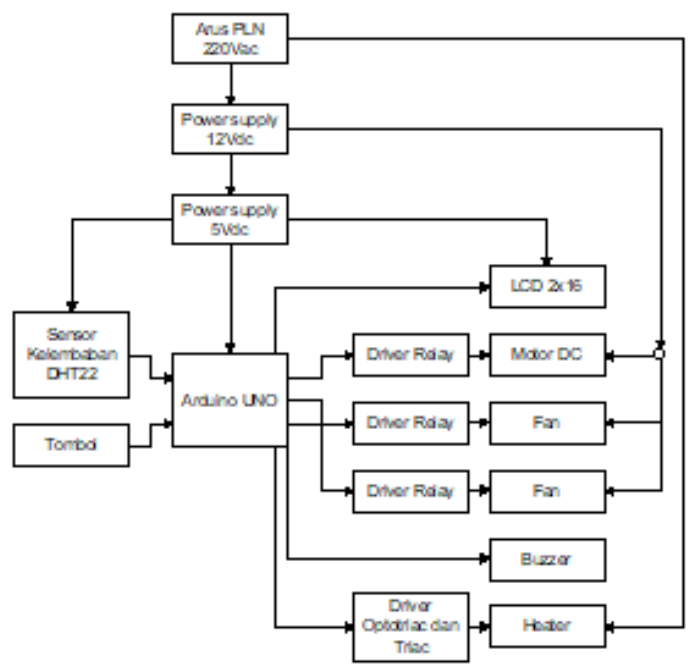

Gambar 1. Block Diagram

Pada blok diagram diatas terdiri dari Mikrokontroller arduino uno sebagai pusat pemprosesan kendali sesuai dengan input yang diberikan, sensor DHT22 digunakan untuk mendeteksi suhu dan kelembaban air pada gabah, driver relay untuk mengaktifkan motor dc, fan, heater digunakan sebagai sumber panas pada alat pengering. Serta LCD digunakan sebagai output untuk menampilkan informasi data suhu dan kelembaban gabah.

\section{B. Flowchart}

Diagram alur merupakan logika atau urutan instruksi program dalam suatu diagram. Diagram alur dapat menunjukan secara jelas arus pengendalian algoritma, yaitu bagaimana rangkaian pelaksanaan kegiatan. Adapun tujuan dari pembuatan diagram alur adalah untuk mengambarkan suatu tahapan penyelesaian masalah secara sederhana, terurai, rapi dan jelas.

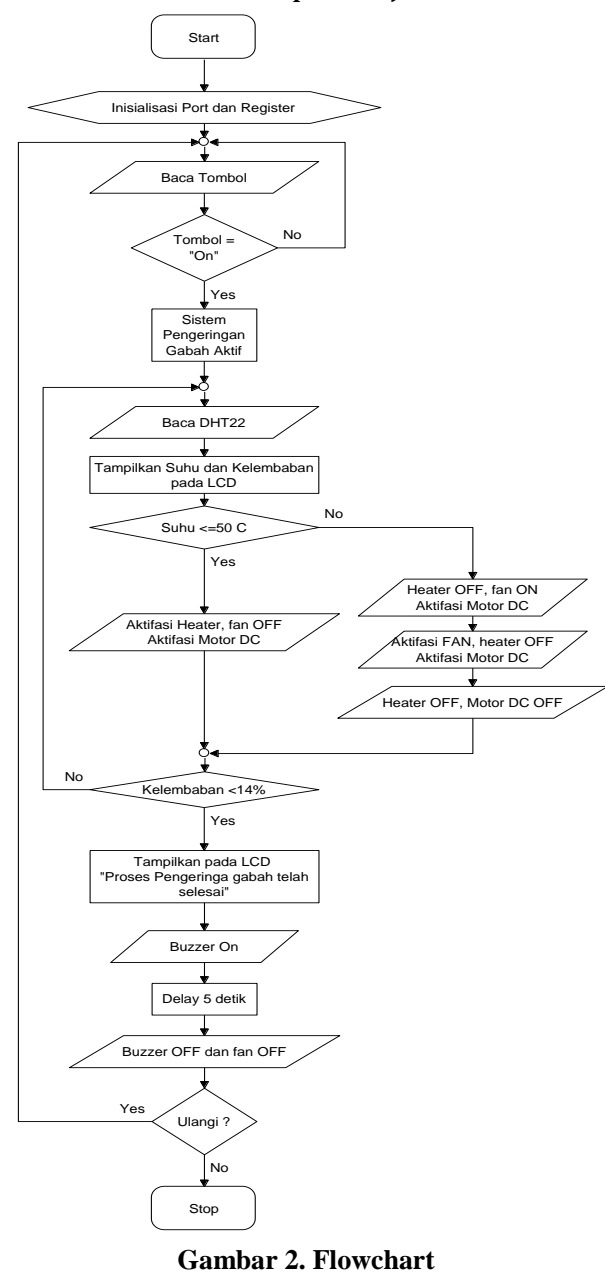

Pada Gambar 2 diatas merupakan flowchart atau diagram alur cara kerja alat secara keseluruhan, sistem diawali dengan inisialisasi port, kemudia sistem akan mendeteksi masing-masing keadaan.

\section{Perancangan Hardware}

Perancangan hardware merupakan suatu tahap atau proses dalam pembuatan suatu perangkat keras. Perancangan hardware bertujuan untuk memudahkan serta mengurangi tingkat kesalahan dalam membuat perangkat keras sehingga mendapatkan hasil yang optimal.

1. Arduino uno Berfungsi sebagai pusat pemprosesan kendali sesuai dengan input yang diberikan.

2. Sensor DHT22 Fungsi dari sensor DHT22 sebagai sensor untuk mendeteksi kelembaban pada alat pengering gabah.

3. Perancangan Mekanikal

Merupakan bentuk dari prototipe alat keseluruhan yang dimana bentuk alat keseluruhan digambar. Dapat dilihat pada gambar 2 . 


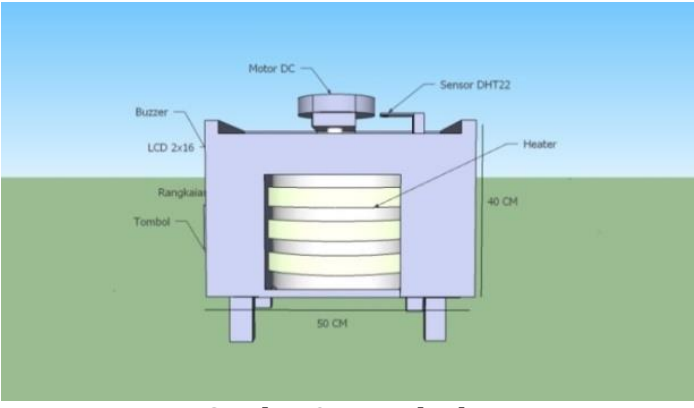

Gambar 3. Bentuk Alat

4. Heater berfungsi sebagai media pengering yang mengeluarkan suhu panas dalam pengeringan gabah.

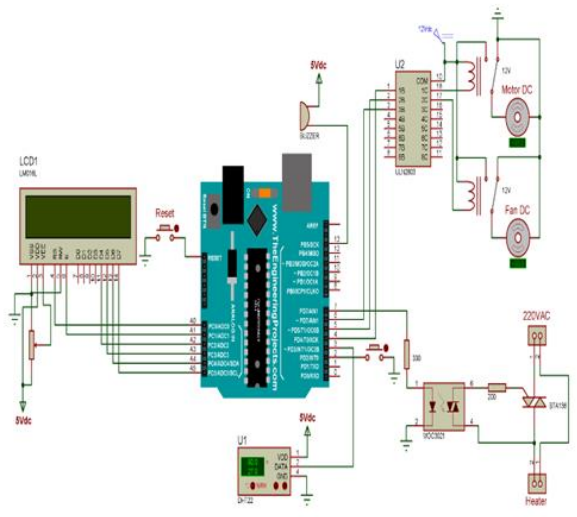

Gambar 4. Rangkaian Keseluruhan

\section{Perancangan Software}

Perancangan software secara keseluruhan pada tugas akhir ini mengunakan Arduino IDE (Integrated Development Environment), yaitu software yang merupakan bawaan dari arduino. Dimana dapat mengendalikan input dan output yang digunakan pada sistem otomatisasi pengering gabah. Pada software Arduino IDE dapat dilakukan proses compire dan upload program yang dibuat ke dalam mikrokontroler arduino. Kode program arduino dibuat mengunakan bahasa pemograman bahasa C. Untuk pemberi informasi antara perangkat dengan pengguna, penulis memberikan input dalam mengatur kontrol otomatis pada alat pengering gabah, serta hasil dari pengaturan akan ditampilkan melalui LCD.

\section{HASIL DAN PEMBAHASAN}

Pada bagian ini untuk membuktikan alat yang telah dibuat dapat berjalan dengan baik atau tidak, maka diperlukan pengujian. Adapun pengujian yang dilakukan yaitu berupa pengujian pada sensor DHT22 apakah sensor berfungsi dengan baik sebagai sensor pembaca suhu dan kelembaban pada gabah dan ruang pemanas sistem pengering gabah.

Proses pengujian alat dilakukan dengan langkah pertama yaitu mengambil gabah padi yang sudah selesai panen yang dimana akan siap untuk di keringkan, hasil dari pembacaan sensor dht22 akan menjadi acuan bagi proses pengeringan gabah yang dimana kontrol motor, heater, fan akan mengacu pada sensor DHT22.

Ruang pengering adalah ruang yang dimana proses pengeringan berbentuk tabung dengan tinggi sekitar 40 $\mathrm{cm}$. Dimana didalam ruang pengering di pasang sensor DHT22 dan sambungan dari pengadukan gabah yang memutar gabah di dalam ruangan pengering. Adapun beberapa pengujian yang penulis lakukan sebagai berikut.
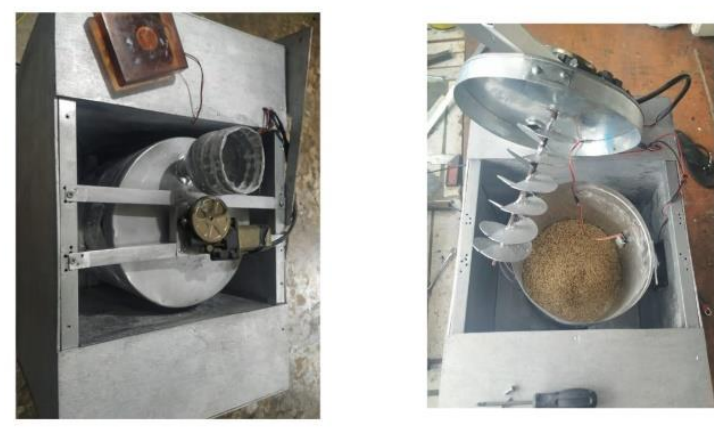

Gambar 5. Tampilan Alat Keseluruhan

A. Pengujian Hardware

1. Pengujian Suhu dengan Sensor DHT22

Hasil pengujian suhu pada sensor DHT22 dengan perbandingan termometer seperti dalam tabel berikut :

Tabel 1. Hasil pengujian sensor suhu DHT22.

\begin{tabular}{|c|c|c|c|c|c|}
\hline \multirow[t]{2}{*}{ No } & \multirow[t]{2}{*}{ Waktu } & \multicolumn{2}{|c|}{ Hasil Pengujian } & \multirow{2}{*}{$\begin{array}{c}\text { Selisih } \\
\text { Error }\end{array}$} & \multirow[t]{2}{*}{ Error \% } \\
\hline & & DHT22 & Thermometer & & \\
\hline 1 & 01.59 & $45^{\circ} \mathrm{C}$ & $53^{\circ} \mathrm{C}$ & 8 & 0,150 \\
\hline 2 & 11.51 & $58^{\circ} \mathrm{C}$ & $55,4^{\circ} \mathrm{C}$ & 2,6 & 0,046 \\
\hline 3 & 20.36 & $60^{\circ} \mathrm{C}$ & $59,6^{\circ} \mathrm{C}$ & 0,4 & 0,067 \\
\hline 4 & 30.47 & $65^{\circ} \mathrm{C}$ & $65,4^{\circ} \mathrm{C}$ & 0,4 & 0,061 \\
\hline 5 & 33.39 & $66^{\circ} \mathrm{C}$ & $66,1^{\circ} \mathrm{C}$ & 0,1 & 0,015 \\
\hline \multicolumn{5}{|c|}{ Rata-Rata Error \% } & 0,067 \\
\hline
\end{tabular}

Berdasarkan data pada tabel 1 merupakan hasil dari pengujian sensor suhu DHT22. Adapun adapun rumus dari perhitungan nilai presentase error dan rata-rata error dari pengukuran suhu menggunakan sensor Dht22 sebagai berikut :

(\%)Error $=\frac{\text { Nilai Sensor }- \text { Nilai Acuan }}{\text { Nilai Acuan }} \times 100 \%$

Dari hasil pengujian sensor suhu DHT22 dapat dilihat pada tabel 1 hasil pembacaan suhu kurang lebih sama dengan alat ukur thermometer sebagai pembanding. Berdasarkan tabel 1 pengujian sensor suhu meliliki ratarata error sebesar 1,695\% dengan demikian sensor suhu DHT22 bekerja dengan baik dan normal.

2. Pengujian Kelembaban dengan Sensor DHT22 Hasil pengujian kelembaban pada sensor dht22 dengan perbandingan thermometer seperti dalam tabel berikut: 
Tabel 2. Hasil Pengujian Kelembaban Sensor DHT22

\begin{tabular}{|c|c|c|c|c|c|}
\hline \multirow{2}{*}{ No } & \multirow{2}{*}{ Waktu } & \multicolumn{2}{|c|}{ Hasil Pengujian } & \multirow{2}{*}{$\begin{array}{c}\text { Selisih } \\
\text { Error }\end{array}$} & Error \% \\
\cline { 3 - 4 } & & DHT22 & Thermometer & 4 & 0,90 \\
\hline 1 & 01.59 & $40^{\circ} \mathrm{C}$ & $44^{\circ} \mathrm{C}$ & 4 & 0,58 \\
\hline 2 & 11.51 & $18^{\circ} \mathrm{C}$ & $17^{\circ} \mathrm{C}$ & 1 & 0 \\
\hline 3 & 20.36 & $16^{\circ} \mathrm{C}$ & $16^{\circ} \mathrm{C}$ & 0 & 0,62 \\
\hline 4 & 30.47 & $15^{\circ} \mathrm{C}$ & $16^{\circ} \mathrm{C}$ & 1 & $0,44 \%$ \\
\hline 5 & 33.39 & $14^{\circ} \mathrm{C}$ & $16^{\circ} \mathrm{C}$ & 2 & $0,44 \%$ \\
\hline \multicolumn{7}{|c|}{ Rata-Rata Error $\%$} \\
\hline
\end{tabular}

Berdasarkan data pada tabel 2 merupakan hasil dari pengujian kelembaban sensor DHT22. Adapun rumus dari perhitungan nilai presentase error dan rata-rata error dari pengukuran suhu menggunakan sensor dht22 sebagai berikut:

$(\%)$ Error $=\frac{\text { Nilai Sensor-Nilai Acuan }}{\text { Nilai Acuan }} \times 100 \%$

Dari hasil pengujian sensor DHT22 dapat dilihat pada tabel 2 hasil pembacaan kelembaban kurang lebih sama dengan alat ukur Thermometer sebagai pembanding. Berdasarkan tabel 2 pengujian kelembaban sensor dht22 rata-rata error sebesar 0,44\% dengan demikian sensor kelembaban DHT22 bekerja dengan baik dan normal.

3. Pengujian lama waktu proses penngeringan $1 \mathrm{Kg}$ Berikut adalah hasil dari lama proses pengeringan gabah padi dari perbandingan perkilo gabah yang akan dikeringkan

Tabel 3. Pengukuran lama waktu proses pengeringan $1 \mathrm{Kg}$

\begin{tabular}{|c|c|c|c|}
\hline \multirow{2}{*}{ No } & \multirow{2}{*}{ Waktu } & \multicolumn{2}{|c|}{ Sensor DHT22 } \\
\cline { 3 - 4 } & & Suhu & Kelembaban \\
\hline 1 & 01.59 & $53^{\circ} \mathrm{C}$ & $40 \%$ \\
\hline 2 & 11.51 & $55,4^{\circ} \mathrm{C}$ & $18 \%$ \\
\hline 3 & 20.36 & $59,6^{\circ} \mathrm{C}$ & $16 \%$ \\
\hline 4 & 30.47 & $65,4^{\circ} \mathrm{C}$ & $15 \%$ \\
\hline 5 & 33.39 & $66,1^{\circ} \mathrm{C}$ & $14 \%$ \\
\hline
\end{tabular}

Dari data tabel percobaan $1 \mathrm{Kg}$ diketahui bahwa kadar air awal $40 \%$ dan untuk menurunkan kadar air dibutuhkan waktu sekitar 33 menit 39 detik dengan setpoint suhu $66,1^{\circ} \mathrm{C}$ dengan demikian sensor DHT22 dapat dikatakan bekerja dengan baik dan normal.

Tabel 4. Lama waktu proses pengeringan gabah $2 \mathrm{Kg}$

\begin{tabular}{|c|c|c|c|}
\hline \multirow{2}{*}{ No } & Waktu & \multicolumn{2}{|c|}{ Sensor DHT22 } \\
\cline { 3 - 4 } & & Suhu & Kelembaban \\
\hline 1 & 00.01 & $29^{\circ} \mathrm{C}$ & $62 \%$ \\
\hline 2 & 11.35 & $57^{\circ} \mathrm{C}$ & $24 \%$ \\
\hline 3 & 21.00 & $66^{\circ} \mathrm{C}$ & $19 \%$ \\
\hline 4 & 34.05 & $67^{\circ} \mathrm{C}$ & $17 \%$ \\
\hline 5 & 44.32 & $69^{\circ} \mathrm{C}$ & $16 \%$ \\
\hline 6 & 1.19 .08 & $69^{\circ} \mathrm{C}$ & $15 \%$ \\
\hline 7 & 1.30 .39 & $69^{\circ} \mathrm{C}$ & $14 \%$ \\
\hline
\end{tabular}

Dari data percobaan $2 \mathrm{Kg}$ diketahui bahwa kadar air awal $62 \%$ untuk menurunkan kadar air dibutuhkan waktu sekitar 90 menit dengan setpoint suhu $69^{\circ} \mathrm{C}$. Dengan demikiran sensor dht22 dapat dikatakan bekerja dengan baik dan normal.

Tabel 5. Lama waktu proses pengeringan gabah $3 \mathbf{~ K g}$

\begin{tabular}{|l|l|l|l|}
\hline \multirow{2}{*}{ No } & Waktu & Sensor DHT22 & \\
\cline { 3 - 4 } & & Suhu & Kelembaban \\
\hline 1 & 01.35 & $48^{\circ} \mathrm{C}$ & $38 \%$ \\
\hline 2 & 40.39 & $59^{\circ} \mathrm{C}$ & $19 \%$ \\
\hline 3 & 51.13 & $62^{\circ} \mathrm{C}$ & $17 \%$ \\
\hline 4 & 1.45 .54 & & \\
\hline 5 & 2.23 .40 & $70^{\circ} \mathrm{C}$ & $14 \%$ \\
\hline
\end{tabular}

Dari data tabel percobaan $3 \mathrm{~kg}$ diketahui bahwa kadar air awal 38\% untuk menurunkan kadar air dibutuhkan waktu sekitar 143 menit dengan setpoint suhu $70^{\circ} \mathrm{C}$ dengan demikian sensor DHT22 dapat dikatakan bekerja dengan baik dan nornal

\section{B. Pengujian Software}

Program merupakan induk sistem kendali yang akan dibuat. Software dari alat ini menggunakan pemograman mikrokontroler dengan bahasa $\mathrm{C}$ dan sebagai compireler dari program adalah software Arduino.

a. List program baca tombol.

tombolstate $=$ digitalRead (tombol);

if (tombolstate $==$ LOW) $\{$ //Jika tombol ditekan

stt=1;// Register status, jika tombol

ditekan stt $=1$

digitalWrite(buzzer, HIGH); // Aktifasi buzzer

delay (100);

digitalWrite(buzzer, LOW) ;// buzzer OFF

digitalWrite(motor, LOW)// Motor ON

(pengaduk)

delay (1000);

\}digitalWrite (motor, HIGH);

Pada list program ini jika tombol ditekan maka nilai $\mathrm{stt}=1$ lalu buzzer hidup selama $100 \mathrm{~ms}$ dan kemudian mati. Setelah buzzer mati motor akan hidup selama $1000 \mathrm{~ms}$, setelah $100 \mathrm{~ms}$ maka motor akan mati

b. List program heater dan fan

int $t=$ (dht.readTemperature ()) ;

int $\mathrm{h}=$ (dht.readHumidity ()$-$ ofset);

// Tampilan LCD Baris 1 tuk penunjuk suhu dan kelembaban

lcd. $\operatorname{set}$ Cursor $(0,0)$;

lcd.print ("T/RH:") ; lcd.print(t) ;

lcd.print ("C / ");

lcd.print (h); lcd.print(" ");

delay (1000);

pada list program diatas nilai t diambil dari nilai (dht.readTemperature) yang menunjukkan sensor dht membaca suhu, untuk nilai h diambil dari nilai (dht.readHumidity) yang menunjukan sensor dht 
membaca kelembaban. Lalu pada LCD akan ditampilkan nilai-nilainya.

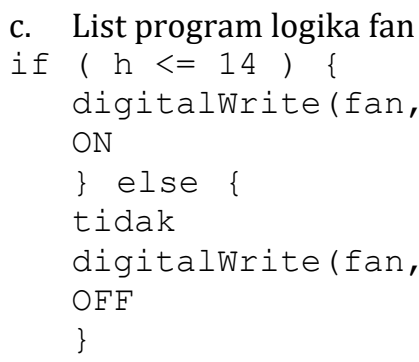
menunjukan suhu diatas dan sama dengan 75 maka heater akan mati dan jika suhu dibawah nilai 75 maka heater akan hidup.

d. List program fan atas

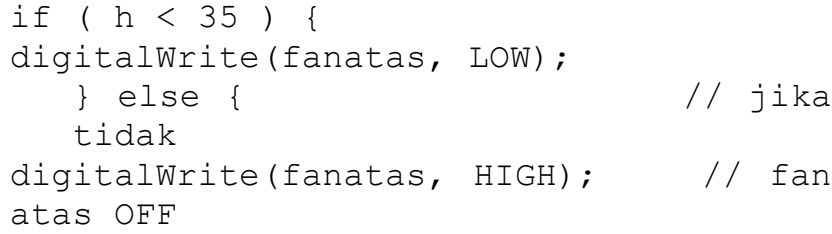

Pada list program diatas jika kelembaban kurang dari 35 maka fan yang terletak diatas akan hidup dan jika nilai kelembaban diatas 35 maka fan atas akan mati, fan diatas berfungsi untuk mengatur sirkulasi udara di dalam alat pengering.

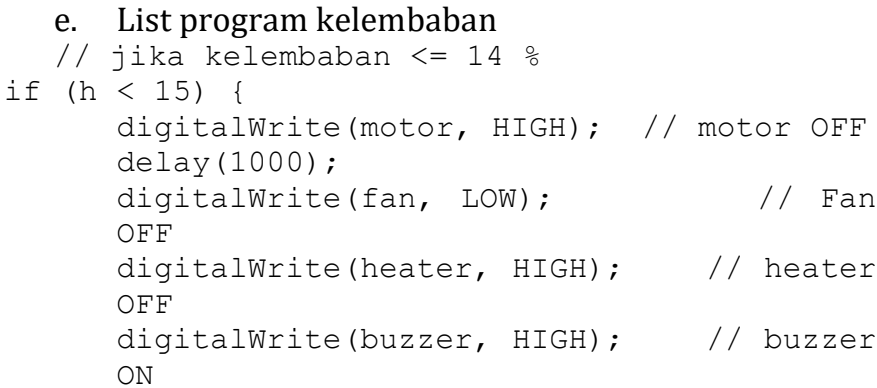

Pada list program diatas jika nilai kelembaban kurang sama dengan 14 maka motor akan mati diikuti dengan fan diatas akan mati setelah delay $1000 \mathrm{~ms}$. Setelah fan atas mati, heater akan mati diikuti oleh buzzer yang berbunyi sebagai penanda bahwa proses pengeringan telah selesai.

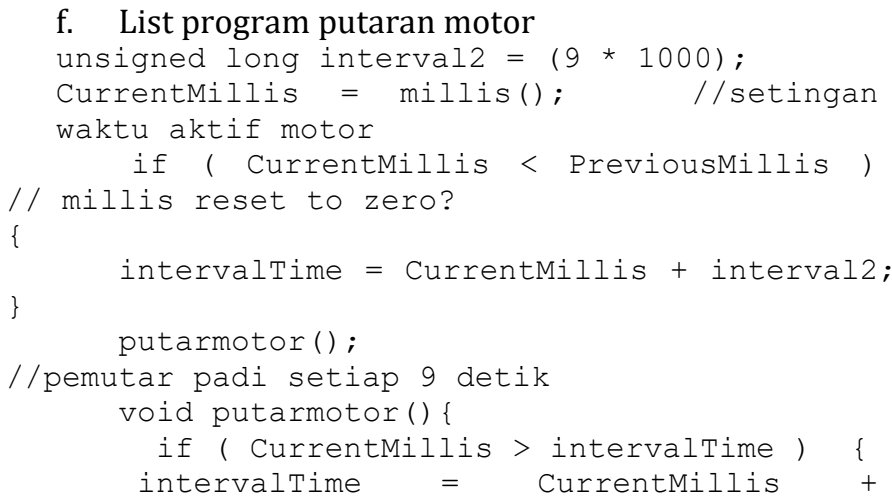

digitalWrite (motor, LOW) ;

ON (pengaduk)

Pada list program diatas jika setingan waktu motor nilai (CurrentMillis) lebih besar dari (IntervalTime) yang bernilai $9 * 1000$ ms yang berarti 9 detik maka motor akan hidup selama 1 detik dimana jeda hidup dan mati motor pengadukan adalah 9 detik.

\section{PENUTUP}

Berdasarkan dari pengujian hardware dan sofware pada alat pengering gabah dengan menggunakan sensor DHT22 sudah bekerja dengan baik. Yang dimana pembacaan Suhu dan kelembaban oleh sensor DHT22 tidak jauh beda dengan pengujian dengan alat ukur thermometer sebagai pembanding. Dengan pengujian yang sudah dilakukan, alat dapat berfungsi dengan sangat baik.

\section{REFERENSI}

[1] M. Hasnan, "Rancang Bangun Sistem Pengering Gabah Dengan Menggunakan Arduino." Universitas Islam Negeri Alauddin Makassar, 2017.

[2] F. Anggraini, A. Suryanto, and N. Aini, "Sistem tanam dan umur bibit pada tanaman padi sawah (Oryza sativa L.) varietas Inpari 13," J. Produksi Tanam., vol. 1, no. 2, 2013.

[3] U. Lazuardi, R. N. Setiadi, and S. Donny, "Sensor Kapasitif Sederhana Untuk Mengukur Tingkat Kelembaban Gabah Padi Berbasis Pengukuran Dielektrik," EKSAKTA, vol. 2, 2011.

[4] K. Iswari, "Kesiapan teknologi panen dan pascapanen padi dalam menekan kehilangan hasil dan meningkatkan mutu beras," J. Penelit. dan Pengemb. Pertan., vol. 31, no. 2, 2013.

[5] E. Van Heriyanto, "TA: Rancang Bangun Alat Pengering Gabah Dengan Pengendali Suhu dan Kelembaban Ruang Berbasis Arduino Uno R3." STIKOM Surabaya, 2014.

[6] B. Septian, T. Latief, And F. Pratama, "Pengaruh Kadar Air Gabah Dan Kelembaban Simpan Terhadap Perubahan Mutu Fisik Beras Giling." Sriwijaya University, 2016.

[7] A. Brillian, Purwanto, and Rahmadwati, "Pengendalian Temperatur pada Proses Pengeringan Gabah Menggunakan Alat Rotary Dryer Berbasis Mikrokontroler Arduino Uno," J. Mhs. Tek. Elektro UB, vol. 1, no. 1, pp. 1-6, 2013.

[8] L. K. Mangalla, "Perancangan pengering gabah menggunakan pemanas udara dari tungku sekam," Metropilar-Jurnal Ilm. Fak. Tek., vol. 6, no. 1, 2008.

M. Kobarsih and N. Siswanto, "Penanganan Susut Panen dan Pasca Panen Padi Kaitannya dengan Anomali Iklim di Wilayah Daerah Istimewa Yogyakarta," PLANTA Trop. J. Agrosains Uournal Agro Sci., vol. 3, no. 2, pp. 100-106, 2015.
M. Al Faris, "Rancang Bangun Prototype Pengering Gabah Otomatis Dengan Pengendali Sensor 
Kelembaban Dan Suhu Berdasarkan Suhu Ruang Berbasis Mikrokontroler ATmega 328," 2019.

\section{Biodata Penulis}

Khairul Hazhar, lahir di Malaysia, 02 Desember 1996. Menyelesaikan Studi DIV Teknik Elektro Industri pada Jurusan Teknik Elektro Fakultas Teknik Universitas Negeri Padang.

Juli Sardi, S.Pd, M.T, Lahir di Dhamasraya, 18 Juli 1987. Menyelesaikan studi S1 di Universitas Negeri Padang tahun 2010, Pendidikan S2 di Institut Tekneologi Sepuluh Nopember tahun 2013. Saat ini terdaftar sebagai dosen pengajar pada jurusan teknik elektro Universitas Negeri Padang. 